\title{
Adenosine(5') Oligophospho-(5') Guanosines and Guanosine(5') Oligophospho-(5') Guanosines in Human Platelets
}

\author{
Hartmut Schlüter, ${ }^{\star}$ Isolde Gro $\beta,{ }^{*}$ Jürgen Bachmann, ${ }^{\star}$ Raimund Kaufmann, ${ }^{\ddagger}$ Marcus van der Giet, ${ }^{*}$ Martin Tepel, ${ }^{\star}$ \\ Jerzy-Roch Nofer," Gerd Assmann," Michael Karas," Joachim Jankowski, ${ }^{,}$and Walter Zidek* \\ ${ }^{*}$ Med. Klinik I, Univ.-Klinik Marienhospital, University of Bochum, Hölkeskampring 40, 44625 Herne; ${ }^{\ddagger}$ Institut für Lasermedizin, \\ University of Düsseldorf, Universitätsstr. 1, 40001 Düsseldorf; "Institut für Biochemie, University of Münster, Wilhelm-Klemm-Str. 2, \\ 48149 Münster; and ${ }^{\mathbb{I}}$ Institut für Klinische Chemie und Laboratoriumsmedizin, University of Münster, Albert-Schweitzer-Str. 33, 48129 \\ Münster, Germany
}

\begin{abstract}
We isolated and identified nucleoside $\left(5^{\prime}\right)$ oligophospho- $\left(5^{\prime}\right)$ nucleosides containing adenosine and guanosine $\left(\mathrm{Ap}_{\mathrm{n}} \mathrm{G} ; \boldsymbol{n}=\right.$ 3-6) as well as diguanosine polyphosphates $\left(\mathrm{Gp}_{n} \mathrm{G} ; \boldsymbol{n}=3-6\right)$ in human platelets. For identification, UV spectrometry, matrix-assisted laser desorption/ionization, postsource decay matrix-assisted laser desorption/ionization mass spectrometry, and enzymatic cleavage experiments were used. The adenosine $\left(5^{\prime}\right)$ oligophospho- $\left(5^{\prime}\right)$ guanosines act as vasoconstrictors and growth factors. The diguanosine polyphosphates are potent modulators of growth in vascular smooth muscle cells, but do not affect vascular tone. $(J$. Clin. Invest. 1998. 101:682-688.) Key words: dinucleoside polyphosphates - platelets - growth factors - cytosolic free $\mathrm{Ca}^{2+}$ concentration $\bullet$ vascular smooth muscle cells
\end{abstract}

\section{Introduction}

It has become increasingly clear that nucleotide derivatives have numerous extracellular effects. A great number of nucleotide receptor subtypes has been established with different physiological effects (1). Among these, cellular growth stimulation has been observed. ATP, for example, has been shown to stimulate proliferation of vascular smooth muscle cells (VSMCs) ${ }^{1}$ and glomerular mesangial cells (2-4). In addition, many vascular effects of nucleotides have been described that vary depending on the purinoceptor subtype activated (5). Recently, the diadenosine polyphosphates were found to be important regulators of vascular tone $(6,7)$ and to activate a receptor that is not sensitive to suramin, and probably represents a novel pu-

Address correspondence to Prof. W. Zidek, Med. Klinik I, Univ.Klinik Marienhospital, University of Bochum, Hölkeskampring 40, 44625 Herne, Germany. Phone: +49 2323499 1670; FAX: +49 2323 499302.

Received for publication 12 August 1996 and accepted in revised form 4 December 1997.

1. Abbreviations used in this paper: $\mathrm{Ap}_{\mathrm{n}} \mathrm{G}$, adenosine $\left(5^{\prime}\right)$ oligophospho-(5')guanosines; $\mathrm{Gp}_{\mathrm{n}} \mathrm{G}$, guanosine $\left(5^{\prime}\right)$ oligophospho-(5')guanosines; PSD-MALDI-MS, postsource decay matrix-assisted laser desorption/ionization mass spectrometry; TEAA, triethyl ammonium acetate; VSMCs, vascular smooth muscle cells.

J. Clin. Invest.

(c) The American Society for Clinical Investigation, Inc. 0021-9738/98/02/0682/07 \$2.00

Volume 101, Number 3, February 1998, 682-688

http://www.jci.org rinoceptor subtype (8). In this study, two further subclasses of dinucleoside polyphosphates are identified in human cells; namely adenosine $\left(5^{\prime}\right)$ oligophospho- $\left(5^{\prime}\right)$ guanosines $\left(\mathrm{Ap}_{\mathrm{n}} \mathrm{G}\right)$ and guanosine $\left(5^{\prime}\right)$ oligo $\left(5^{\prime}\right)$ guanosines $\left(\mathrm{Gp}_{n} \mathrm{G} ; n=3-6\right)$. Furthermore, we attempted to elucidate for the first time the biological effects of these compounds. The action of the substances identified on the vasculature of the isolated perfused rat kidney and the ability to promote growth of vascular smooth muscle cells were also studied.

\section{Methods}

Purification of dinucleoside polyphosphates from human platelets. Dinucleoside polyphosphates were isolated from human platelets unsuitable for transfusion. The platelets were suspended in an isotonic salt solution and centrifuged at 2,500 $\mathrm{g}$ for $5 \mathrm{~min}$. The pellet was resuspended in isotonic salt solution and centrifuged again $(2,500 \mathrm{~g}$ for $5 \mathrm{~min}$ ). The supernatant was aspirated, and the platelet pellet was frozen to $-30^{\circ} \mathrm{C}$ and rethawed in bidistilled water. Then the resulting suspension was deproteinized (step 1) with $0.6 \mathrm{M}$ perchloric acid (final concentration). After adjusting the $\mathrm{pH}$ to 7.0 with $5 \mathrm{M} \mathrm{KOH}$, the precipitated proteins and $\mathrm{KClO}_{4}$ were removed by centrifugation. $40 \mathrm{mM}$ triethylammonium acetate was added to the supernatant (TEAA, final concentration), and the mixture was loaded to a preparative reversed phase column (step 2, LiChroprep RP-18 B; Merck, Darmstadt, Germany; equilibration and sample buffer: $40 \mathrm{mM}$ TEAA in water; flow rate: $5 \mathrm{ml} / \mathrm{min}$ ). By this procedure, dinucleoside polyphosphates are eluted from the reversed phase column where most hydrophobic constituents are bound. The lyophilized eluate, dissolved in $1 \mathrm{M}$ ammonium acetate, $\mathrm{pH} 9.5$, was loaded to a phenyl boronic acid gel (step 3) according to Barnes et al. (eluent: $1 \mathrm{mM} \mathrm{HCl}$; flow rate: $1 \mathrm{ml} /$ $\min ;$ 9).

The lyophilized eluate from the phenyl boronic acid gel was chromatographed (step 4) on an anion exchange column (MonoQ h 5/5, $\mathrm{Cl}^{-}$-form; Pharmacia LKB Biotechnology, Piscataway, NJ; eluent A: $10 \mathrm{mM} \mathrm{K}_{2} \mathrm{HPO}_{4}$, pH 7; eluent B: $50 \mathrm{mM} \mathrm{K}_{2} \mathrm{HPO}_{4}, \mathrm{pH} 7$ with $1 \mathrm{M}$ $\mathrm{NaCl}$; gradient, 0-10 min: 0-10\% B; 10-60 min: 10-40\% B; 60-70 min, $40-100 \% \mathrm{~B}$; flow rate: $0.5 \mathrm{ml} / \mathrm{min}$ ). Fractions were collected according to the UV absorbance profile (peak fractionation). Each fraction from the anion exchange column with a significant UV absorbance was further fractionated (step 5) with a reversed phase column (Superspher RP-18 end-capped, $250 \times 4 \mathrm{~mm}$; Merck; eluent A: $40 \mathrm{mM}$ TEAA in water; eluent B: acetonitrile; gradient, 0-4 min: 0-4\% B; 4-64 min, $4-11 \% \mathrm{~B}$; $64-70 \mathrm{~min}, 11-70 \% \mathrm{~B}$; flow rate: $0.5 \mathrm{ml} / \mathrm{min}$ ). All fractions corresponding to the main $\mathrm{UV}_{254 \mathrm{~nm}}$-absorbing peaks were rechromatographed (step 6) on the reversed phase column (conditions as in step 5).

Postsource decay matrix-assisted laser desorption/ionization mass spectrometry (PSD-MALDI-MS). Sample preparation for PSDMALDI-MS and configuration of the mass spectrometer was described earlier $(10,11)$.

Synthesis of adenosine $\left(5^{\prime}\right)$ oligophospho-(5')guanosine and guanosine (5')oligophospho-(5')guanosine compounds $A p_{n} G, n=3-6$. $\mathrm{Ap}_{\mathrm{n}} \mathrm{G}(n=3-6)$ were synthesized according to $\mathrm{Ng}$ and Orgel (12) using ADP, ATP, GDP, and GTP as substrates. The authors suggested 
that the water-soluble carbodiimide attacks mononucleotides, forming $N$-phosphorylureas. The presence of $\mathrm{Mg}^{2+}$ catalyzes the nucleophilic attack of one phosphate anion on the activated derivative ( $N$-phosphorylurea) resulting in dinucleosid polyphosphates (12). 10 $\mathrm{mM}$ of each nucleotide were mixed with 2.5 M 1-ethyl-3-(3-dimethylaminopropyl)carbodiimide (Sigma Chemical Co., St. Louis, MO) in an aqueous solution containing $2 \mathrm{M}$ Hepes and $50 \mathrm{mM} \mathrm{MgCl}$. The $\mathrm{pH}$ was adjusted to 6.5 , and the reaction mixture was incubated for $24 \mathrm{~h}$ at $37^{\circ} \mathrm{C}$. Then, the $A p_{n} G$ generated during the incubation were concentrated on a preparative $\mathrm{C} 18$ reversed-phase gel (Lichroprep A; Merck). The $A_{p_{n}} G$ were eluted from the column with $30 \%$ acetonitrile, and the eluate was lyophilized. The lyophilizate was dissolved in $10 \mathrm{mM} \mathrm{K}_{2} \mathrm{HPO}_{4}, \mathrm{pH} 7$ (eluent A), and was fractionated with an anion exchange column as described above (purification of dinucleoside polyphosphates from human platelets, step 4). Each fraction from the anion exchange column that showed a significant UV absorbance was further fractionated with a reversed phase column as described above (step 5) and rechromatographed if necessary as in step 6. The $A p_{n}$ Gs were identified with MALDI-MS, with enzymatic cleavage with $5^{\prime}$-nucleotidase from Crotalus durissus and alkaline phosphatase (see enzymatic cleavage experiments). The enzymatic experiments were done to show that the dinucleoside polyphosphates contained $5^{\prime}-5^{\prime}$ ribose phosphate esters.

Enzymatic cleavage experiments. 200-ng aliquots of the fractions from the anion exchange column, purified twice with reversed-phase chromatography (step 5 and 6 of the purification procedure), were incubated with enzymes as follows: the samples were dissolved $(a)$ in $20 \mu \mathrm{l} 200 \mathrm{mM}$ Tris buffer ( $\mathrm{pH}$ 8.9) and incubated with 5'-nucleotide hydrolase (3 mU; from Crotalus durissus, EC 3.1.15.1, from Boehringer Mannheim, Mannheim, Germany, purified according to Sulkowski \& Laskowski [13] for $9 \mathrm{~min}$ at $37^{\circ} \mathrm{C}$ ); (b) in $20 \mu \mathrm{l} 200 \mathrm{mM}$ Tris and $20 \mathrm{mM}$ EDTA buffer ( $\mathrm{pH} 7.4$ ) and incubated with $3^{\prime}$-nucleotide hydrolase (1 mU; from calf spleen, EC 3.1.16.1; Boehringer Mannheim) for $1 \mathrm{~h}$ at $37^{\circ} \mathrm{C}$; and (c) in $20 \mu \mathrm{l} 10 \mathrm{mM}$ Tris, $1 \mathrm{mM} \mathrm{ZnCl}_{2}$, and $1 \mathrm{mM} \mathrm{MgCl} 2$ buffer ( $\mathrm{pH} 8$ ) and incubated with alkaline phosphatase (1 mU; EC 3.1.3.1 from calf intestinal mucosa; Boehringer Mannheim) for $1 \mathrm{~h}$ at $37^{\circ} \mathrm{C}$. The reaction was terminated by ultrafiltration with a centrifuge filter (exclusion limit $10 \mathrm{kD}$ ). After filtration of the enzymatic cleavage products, the filtrate, dissolved in $980 \mu$ l eluent A, was subjected to the anion exchange chromatography on a MiniQ PC 3.2/3 (Pharmacia LKB Biotechnology; eluent A, $10 \mathrm{mM} \mathrm{K}_{2} \mathrm{HPO}_{4}$, $\mathrm{pH}$ 7; eluent $\mathrm{B}, 50 \mathrm{mM} \mathrm{K} \mathrm{HPO}_{4}$, $\mathrm{pH} 7$ with $1 \mathrm{M} \mathrm{NaCl}$; gradient, 0-3 min: $0 \% \mathrm{~B} ; 3-20 \mathrm{~min}: 0-50 \% \mathrm{~B} ; 20-21 \mathrm{~min}: 50-100 \% \mathrm{~B}$; flow rate: 100 $\mu \mathrm{l} / \mathrm{min})$.

Cell proliferation assay. Vascular smooth muscle cells (VSMCs) from normotensive Wistar-Kyoto rats were subcultured in 96-well dishes (Falcon Labware, Cockeysville, MD) at a density of $5 \times 10^{4}$ cells/ $\mathrm{ml}$ and kept in culture medium containing $10 \%$ FCS to reach a subconfluent monolayer. After $24 \mathrm{~h}$, the cells were growth-arrested in $0.5 \%$ FCS for $48 \mathrm{~h}$ without affecting cell adherence to culture wells or viability as checked by Trypan blue vital dye exclusion. Quiescent VSMCs were then exposed to fresh culture medium with $0.5 \%$ FCS with and without the tested agonists for another 48-h incubation period. Cell proliferation was measured using the $\left[{ }^{3} \mathrm{H}\right]$ thymidine incorporation rate as described elsewhere (14).

Measurements of perfusion pressure in the isolated perfused rat kidney. The effect of dinucleoside polyphosphates on vascular tone was evaluated in the isolated rat kidney perfused with a constant flow of $10 \mathrm{ml} / \mathrm{min}$ while perfusion pressure was continuously monitored. Details of the preparation have been given elsewhere (15).

Quantitation of dinucleoside polyphosphates. The fate of dinucleoside polyphosphates during their passage through the isolated perfused rat kidney was studied by collecting $10 \mathrm{ml}$ of the effluate directly after each bolus injection of the individual dinucleoside polyphosphates $(10 \mu \mathrm{M})$. For comparison, equal amounts of the nonhydrolyzable nucleotide $\alpha, \beta$ methylene ATP were injected.

Degradation of dinucleoside polyphosphates by VSMCs was measured by incubating subconfluent quiescent cells in 96-well plates (density of $5 \times 10^{4}$ cells $/ \mathrm{ml}$ ) washed three times with PBS and incubated with $10 \mu \mathrm{M}$ dinucleoside polyphosphates in HBSS for different time periods.

To the effluate from the isolated perfused rat kidney and the supernatant from cell culture, respectively, perchloric acid ( $0.6 \mathrm{M}$ final concentration) was added immediately. After removal of perchlorate by titrating the supernatants to $\mathrm{pH} 8$ with $\mathrm{KOH}$, centrifugation, and adding TEAA (final concentration, $40 \mathrm{mM}$ ), the samples were desalted with a reversed-phase column (effluate from the isolated perfused rat kidney: preparative reversed phase column as described in
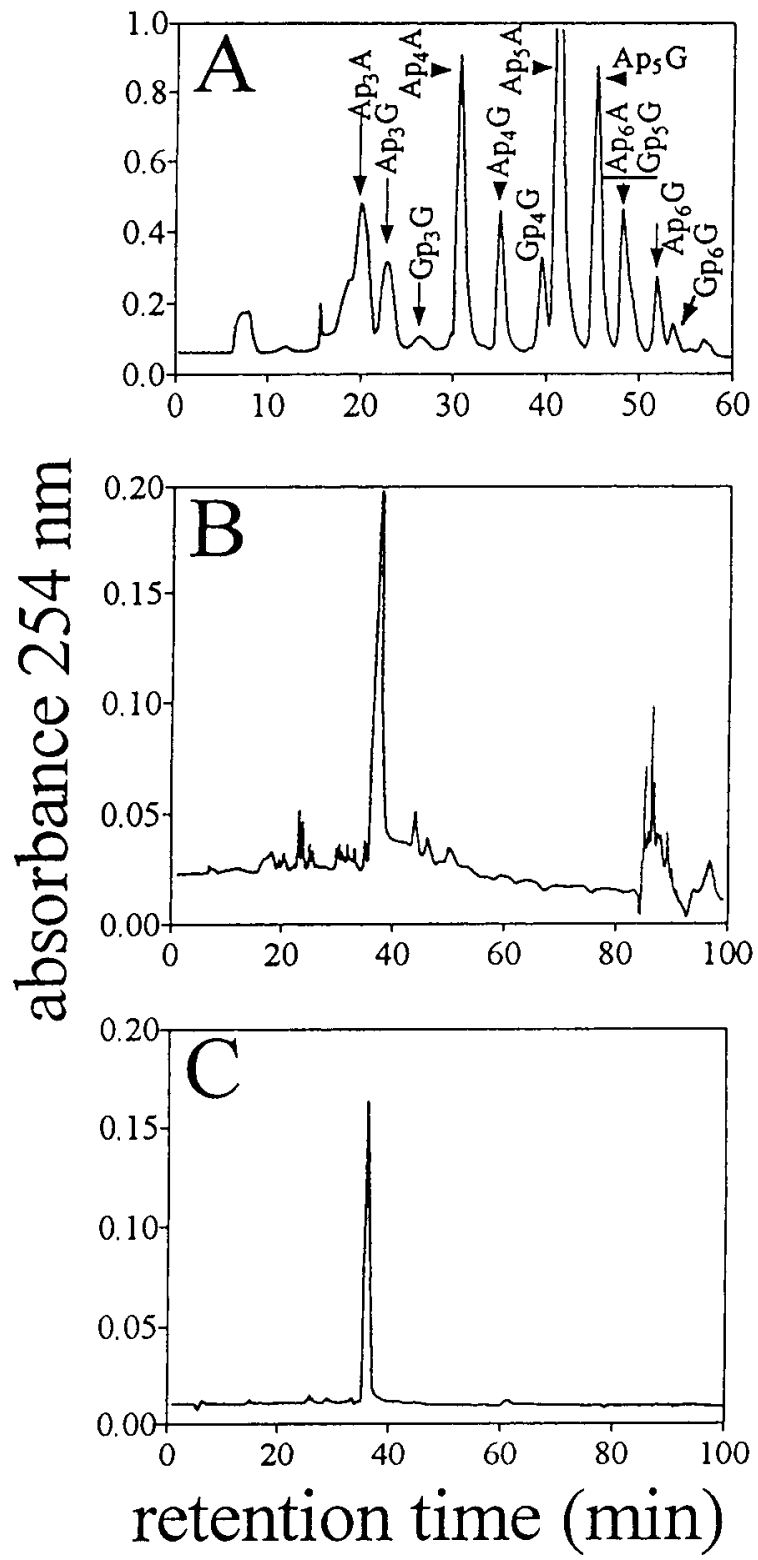

Figure 1. Chromatograms of the purification of the dinucleoside polyphosphates from a platelet extract. $(A)$ Anion exchange chromatography of a platelet extract (step 4). The peaks in $A$ are labeled with abbreviations of the substances identified in the respective fraction. The effluents of all chromatographies were peak-fractionated. (B) Typical reversed phase chromatography (step 5) of a fraction from the anion exchange column (fraction-labeled $\mathrm{Ap}_{6} \mathrm{G}$ in $A$ ). (C) Rechromatography of the fraction corresponding to the UV254-nm absorbing peak at $36 \mathrm{~min}$ (step 6) with the reversed phase column. $A p_{n} \mathrm{~A}$, adenosine (5')oligophospho-(5') adenosines. 
step 2; supernatants: Superspher RP-18 end-capped, $250 \times 4 \mathrm{~mm}$; Merck; eluent A, $40 \mathrm{mM}$ TEAA in water; eluent B, 20\% acetonitrile). Chromatographic analysis was done with the anion exchange HPLC described under "enzymatic cleavage experiments". The intact dinucleoside polyphosphates and $\alpha, \beta$ methylene ATP were quantitated by integrating the respective UV peaks.

Incubation of the platelets with thrombin and purification of the dinucleoside polyphosphates from the supernatant. Platelets from three platelet concentrates, each from 21 whole blood were suspended in $300 \mathrm{ml}$ of a physiological salt solution and divided into two parts. The first part was incubated with thrombin $(0.05 \mathrm{U} / \mathrm{ml})$ for $1 \mathrm{~min}$. After incubation, the platelets were removed by centrifugation $(2,500 \mathrm{~g}$ for $5 \mathrm{~min}$ ). The supernatant was deproteinized with perchloric acid. The second part was deproteinized with perchloric acid. The supernatants of both parts were chromatographed according to step 2 to step 6 . The gradient of the anion exchange chromatography (step 4) was modified as follows: gradient, $0-10 \mathrm{~min}$ : $0-5 \% \mathrm{~B} ; 10-100 \mathrm{~min}, 5-35 \%$ B; $100-105 \mathrm{~min}, 35-40 \% \mathrm{~B}$; $105-110 \mathrm{~min}, 40-100 \%$ B. The purified substances were identified with PSD-MALDI-MS as described above. The concentrations of the dinucleoside polyphosphates were estimated plotting known concentrations of the respective substances against their UV absorbance at $254 \mathrm{~nm}$. To estimate the recovery of the dinucleoside polyphosphates after extraction and chromatography, $\left[{ }^{3} \mathrm{H}\right] \mathrm{Ap}_{4} \mathrm{~A}$ (Amersham Corp., Arlington Heights, IL) was added to the untreated platelets.

As a control, the same experiment and the same chromatographic procedure as described above were performed except that instead of thrombin, an equal volume of physiological salt solution was added.

\section{Results}

In the following experiment, purification and identification of the dinucleoside polyphosphates from human platelets is exemplified for $\mathrm{Ap}_{6} \mathrm{G}$. Fig. 1 shows chromatographic purification of $\mathrm{Ap}_{6} \mathrm{G}$ from human platelets. In the last chromatographic step, a single UV peak was obtained. The substance underlying this peak was identified by the following results: (a) MALDI-MS revealed a mass of $1013 \mathrm{D}$ (Fig. 2). (b) After addition of $1 \mathrm{mM}$ $\mathrm{NaCl}$, MALDI-MS showed seven additional signals corresponding to masses of $1013+n \times 22 \mathrm{D}$ ( $n$ from 1 to 7 , data not

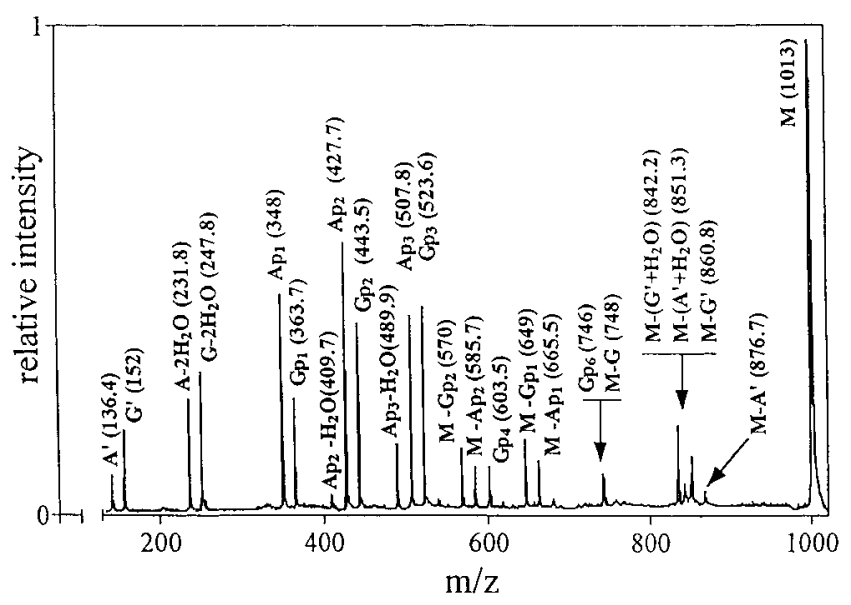

Figure 2. Mass spectrometric analysis of the purified fractions from platelets. Typical positive-ion mass spectrum measured with the PSDMALDI-MS of the UV-absorbing fraction shown in Fig. $1 C$ (abscissa: relative mass/charge, $\mathrm{m} / \mathrm{z}, \mathrm{z}=1$; ordinate: relative intensity). The abbreviations used as labels of the fragments are explained in Table I.
Table I. Masses of the Fragment Ions (in D) Obtained by PSD-MALDI Mass Spectrometry of Each Dinucleoside Polyphosphate Isolated

\begin{tabular}{|c|c|c|c|c|c|c|c|c|}
\hline Fragment ions & $\mathrm{Ap}_{3} \mathrm{G}$ & $\mathrm{Gp}_{3} \mathrm{G}$ & $\mathrm{Ap}_{4} \mathrm{G}$ & $\mathrm{Gp}_{4} \mathrm{G}$ & $\mathrm{Ap}_{5} \mathrm{G}$ & $\mathrm{Gp}_{5} \mathrm{G}$ & $\mathrm{Ap}_{6} \mathrm{G}$ & $\mathrm{Gp}_{6} \mathrm{G}$ \\
\hline $\mathrm{A}^{\prime}$ & 136 & & 136 & & 136 & & 136 & \\
\hline $\mathrm{G}^{\prime}$ & 152 & 152 & 152 & 152 & 152 & 152 & 152 & 152 \\
\hline $\mathrm{A}-2 \mathrm{H}_{2} \mathrm{O}$ & 232 & & 232 & & 232 & & 232 & \\
\hline $\mathrm{G}-2 \mathrm{H}_{2} \mathrm{O}$ & 248 & 248 & 248 & 248 & 248 & 248 & 248 & 248 \\
\hline $\mathrm{Ap}_{1}$ & 348 & & 348 & & 348 & & 348 & \\
\hline $\mathrm{Gp}_{1}$ & 363 & 364 & 364 & 364 & 364 & 364 & 364 & 364 \\
\hline $\mathrm{Ap}_{2}-\mathrm{H}_{2} \mathrm{O}$ & 409 & & 410 & & & & & \\
\hline $\mathrm{Ap}_{2}$ & 428 & & 427 & & 427 & & 428 & \\
\hline $\mathrm{Gp}_{2}$ & 444 & 444 & 444 & 444 & 443 & 444 & 444 & 444 \\
\hline $\mathrm{Ap}_{3}-\mathrm{H}_{2} \mathrm{O}$ & & & 490 & & 490 & & 490 & \\
\hline $\mathrm{Ap}_{3}$ & & & 507 & & 508 & & 508 & \\
\hline $\mathrm{Gp}_{3}$ & & & 523 & 523 & 523 & 523 & 523 & 523 \\
\hline $\mathrm{M}-\mathrm{Gp}_{2}$ & 330 & & 410 & & 490 & 506 & 570 & 585 \\
\hline $\mathrm{M}-\mathrm{Ap}_{2}$ & & & & & 505 & & 585 & \\
\hline $\mathrm{M}-\mathrm{Gp}_{1}$ & 410 & 425 & 490 & 506 & 569 & 586 & 650 & 665 \\
\hline$M-A p_{1}$ & & & 505 & & 585 & & 666 & \\
\hline$M-A$ & & & 587 & & 666 & & 747 & \\
\hline $\mathrm{M}-\mathrm{G}+\mathrm{H}_{2} \mathrm{O}$ & 604 & 524 & 683 & 604 & 762 & 684 & 843 & 763 \\
\hline $\mathrm{M}-\mathrm{A}^{\prime}-\mathrm{H}_{2} \mathrm{O}$ & 621 & & 701 & & 780 & & 861 & \\
\hline $\mathrm{M}-\mathrm{G}^{\prime}-\mathrm{H}_{2} \mathrm{O}$ & & 620 & & 701 & & 780 & & 859 \\
\hline $\mathrm{M}-\mathrm{G}^{\prime}$ & 622 & 638 & 701 & 718 & 782 & 797 & 861 & 877 \\
\hline$M-A^{\prime}$ & 638 & & 717 & & 797 & & 877 & \\
\hline M & 773 & 789 & 853 & 869 & 933 & 949 & 1013 & 1029 \\
\hline
\end{tabular}

From the characteristic fragmentation patterns, the structure of each dinucleoside polyphosphate can be deduced. The dinucleoside polyphosphates are listed in the first line. The masses of the fragment ions obtained from each dinucleoside polyphosphate by PSD MALDI mass spectrometry are shown in the columns. The left column labeled "fragment ions" shows the fragments, which could be assigned to the masses obtained after fragmentation. $M$, protonated parent ion, $A^{\prime}$, adenine, $G^{\prime}$, guanine, A, adenosine, $G$, guanosine, $p$, phosphate group, e.g., $\mathrm{Ap}_{3}$, adenosine triphosphate.

shown). This result indicates six negative charges in the molecule. (c) PSD-MALDI-MS revealed a fragmentation pattern that was identical with that of synthetic $\mathrm{Ap}_{6} \mathrm{G}$ (Fig. 2). The fragmentation yields a pattern characteristic of each substance. Interpretation of the fragment ions is listed in Table I. $(d)$ Cleavage of the molecule with 5 '-nucleotide hydrolase (Crotalus durissus) yielded AMP and guanosine pentaphosphate as well as GMP and adenosine pentaphosphate, as evidenced by the retention times and UV spectra (Fig. 3). The cleavage pattern was identical with that of synthetic $\mathrm{Ap}_{6} \mathrm{G}$. (e) Incubation of the molecule with $3^{\prime}$-nucleotide hydrolase (calf spleen) and alkaline phosphatase yielded no cleavage products. The enzymatic cleavage experiments demonstrate that the polyphosphate chain interconnects the nucleosides adenosine and guanosine via phosphoester bonds with the $5^{\prime}$-oxygens of the riboses.

In an analogous manner, $A p_{3} G, A p_{4} G$, and $A p_{5} G$ as well as $\mathrm{Gp}_{3} \mathrm{G}, \mathrm{Gp}_{4} \mathrm{G}, \mathrm{G} \mathrm{p}_{5} \mathrm{G}$, and $\mathrm{Gp}_{6} \mathrm{G}$ were purified and identified from the various anion exchange chromatography fractions indicated in Fig. $1 \mathrm{~A}$. Table I presents the signal pattern of PSD-MALDI-MS fragmentation of the various dinucleoside 


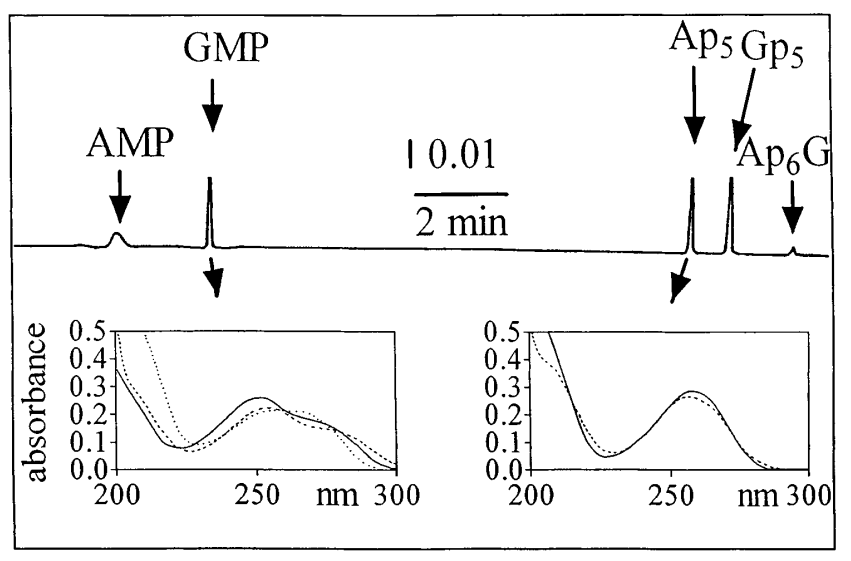

Figure 3. Anion exchange chromatography of the enzymatic cleavage products after incubation of the fraction labeled $\mathrm{Ap}_{6} \mathrm{G}$ in Fig. $1 C$ with the $5^{\prime}$-nucleotide hydrolase. The inserts show the UV spectra of the fractions indicated by the arrows (solid line, $\mathrm{pH} 6.4$ [water], dashed lines, $\mathrm{pH} 2[0.01 \mathrm{M} \mathrm{HCl}]$, dotted lines, $\mathrm{pH} 11(10 \mathrm{mM} \mathrm{NaOH})$. The spectra correspond to those of adenosine and guanosine. The peaks labeled AMP and $\mathrm{Gp}_{5}$ showed UV spectra identical with those of $\mathrm{Ap}_{5}$ and GMP, respectively.

polyphosphates. Table II lists the retention times of the dinucleoside polyphosphates and their cleavage products after incubating the different dinucleoside polyphosphates with the 5 '-nucleotide hydrolase (Crotalus durissus). The alkaline phosphatase and the 3 '-nucleotide hydrolase did not degrade any of the molecules.

What is the physiological significance of this family of compounds? $\mathrm{Ap}_{5} \mathrm{G}$ and $\mathrm{Ap}_{6} \mathrm{G}$ constrict the renal vasculature in concentrations $\geq 10^{-7} \mathrm{M}$ (Fig. $4, A$ and $B$ ). The vasoconstrictive actions of these agents may also be elicited indirectly by their degradation products. To test this possibility, adenosine

Table II. Retention Time (min) of the Reaction Products After Incubation of the Different Fractions from the Platelet Extract with the 5'-Nucleotide Hydrolase (Crotalus Durissus)

\begin{tabular}{lccccccccc}
\hline & $\mathrm{Ap}_{3} \mathrm{G}$ & $\mathrm{Gp}_{3} \mathrm{G}$ & $\mathrm{Ap}_{4} \mathrm{G}$ & $\mathrm{Gp}_{4} \mathrm{G}$ & $\mathrm{Ap}_{5} \mathrm{G}$ & $\mathrm{Gp}_{5} \mathrm{G}$ & $\mathrm{Ap}_{6} \mathrm{G}$ & $\mathrm{Gp}_{6} \mathrm{G}$ & Standards \\
\hline $\mathrm{Ap}_{1}$ & 9.03 & & 9.04 & & 9.05 & & 9.04 & & 9.04 \\
$\mathrm{Ap}_{3}$ & & & 11.89 & & & & & & 11.87 \\
$\mathrm{Gp}_{3}$ & & & 12.57 & 12.55 & & & & & 12.54 \\
$\mathrm{Ap}_{4}$ & & & & & 13.23 & & & & \\
$\mathrm{Gp}_{1}$ & 10.16 & 10.18 & 10.17 & 10.16 & 10.16 & 10.18 & 10.17 & 10.17 & 10.16 \\
$\mathrm{Ap}_{2}$ & 10.63 & & & & & & & & 10.65 \\
$\mathrm{Gp}_{2}$ & 11.15 & 11.16 & & & & & & 11.13 & 13.25 \\
$\mathrm{Gp}_{4}$ & & & & & 13.91 & 13.90 & & & 13.93 \\
$\mathrm{Ap}_{5}$ & & & & & & & 15.32 & & 15.33 \\
$\mathrm{Gp}_{5}$ & & & & & & & 15.69 & 15.73 & 15.70 \\
$\mathrm{~Np}_{\mathrm{x}} \mathrm{N}^{\mathrm{P}}$ & 12.07 & 12.91 & 13.94 & 14.73 & 15.63 & 16.05 & 16.57 & 17.40 & \\
$\mathrm{~Np}_{\mathrm{x}} \mathrm{N}^{\mathrm{A}}$ & 12.08 & 12.90 & 13.94 & 14.70 & 15.65 & 16.02 & 16.59 & 17.43 & \\
& & & & & & & & &
\end{tabular}

The left column shows the reaction products that could be assigned to each peak according to its retention time. For comparison, the retention times of the authentic reaction products are shown in the right column, and those of the dinucleoside polyphosphates are shown in the last row. $\mathrm{Np}_{\mathrm{x}} \mathrm{N}^{\mathrm{P}}$, uncleaved fraction purified from platelets; $\mathrm{Np}_{\mathrm{x}} \mathrm{N}^{\mathrm{A}}$, uncleaved authentic dinucleoside polyphosphate.
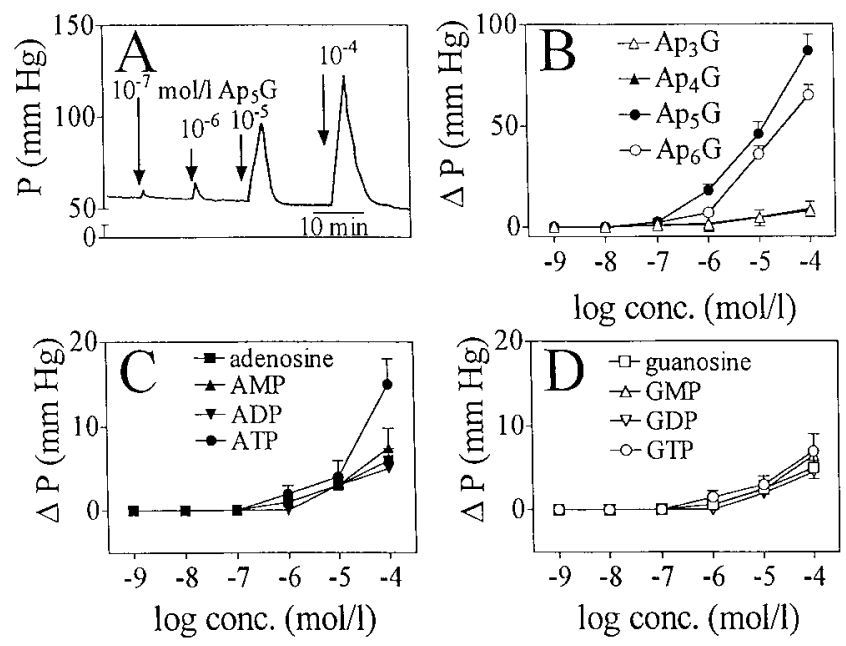

Figure 4. Effects of adenosine(5')oligophospho-(5')guanosines and guanosine (5')oligophospho-(5')guanosines $\left(\mathrm{Ap}_{\mathrm{n}} \mathrm{G}, \mathrm{Gp}_{\mathrm{n}} \mathrm{G}, n=3-6\right)$ as well as of potential degradation products on perfusion pressure in an isolated perfused rat kidney. Data are means \pm SD. $(A)$ Changes in perfusion pressure $P$ (ordinate) after bolus injections of $100 \mu l$ physiological salt solution containing the indicated concentrations of $\mathrm{Ap}_{5} \mathrm{G}$. (B) Concentration-response curves showing the changes in perfusion pressure $(\Delta P)$ after bolus injections of $A p_{n}$ Gs as described in $A$. $(C)$ Concentration-response curves showing the changes in perfusion pressure $(\Delta P)$ after bolus injections of adenosine, AMP, ADP, and ATP as described in $A$. (D) Concentration-response curves showing the changes in perfusion pressure $(\Delta P)$ after bolus injections of guanosine, GMP, GDP, and GTP as described in $A$.

and guanosine containing mononucleotides as well as both nucleosides were examined. All potential degradation products showed much weaker vasoconstrictive effects than those of the $\mathrm{Ap}_{5} \mathrm{G}$ and $\mathrm{Ap}_{6} \mathrm{G}$ (Fig. 4, $C$ and $D$ ), indicating that the vasoconstrictive action of the latter is direct rather than indirect. $A p_{3} G$ and $A p_{4} G$ were very weak vasoconstrictors, and $G p_{n}$ Gs did not affect vascular tone (data not shown). Furthermore, both

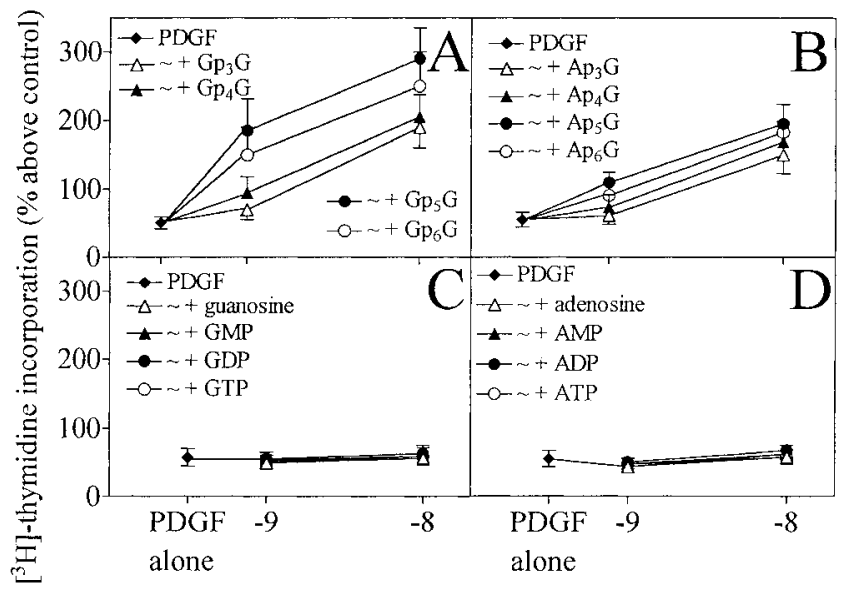

Figure 5. $\left[{ }^{3} \mathrm{H}\right]$ Thymidine incorporation rate (ordinate) in \% above control in VSMCs incubated with various concentrations of dinucleoside polyphosphates $\left(A, \mathrm{Gp}_{\mathrm{n}} \mathrm{G} ; B, \mathrm{Ap}_{\mathrm{n}} \mathrm{G}\right)$ and of potential degradation products $(C$ and $D)$ with $5 \mathrm{ng} / \mathrm{ml}$ PDGF. Growth stimulation with $5 \mathrm{ng} / \mathrm{ml}$ PDGF alone was plotted for comparison. Abscissae: $\log$ of concentration in $\mathrm{M}$. 


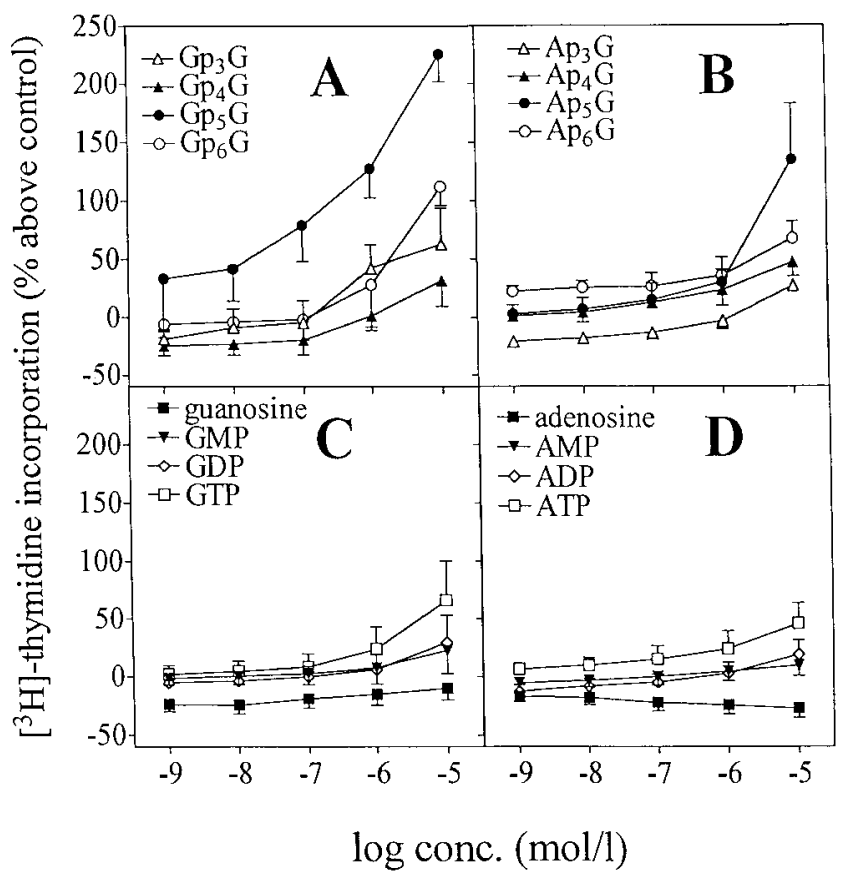

Figure 6. $\left[{ }^{3} \mathrm{H}\right]$ Thymidine incorporation rate (ordinate) in \% above control in VSMCs incubated with various concentrations of dinucleoside polyphosphates $\left(A, \mathrm{Gp}_{\mathrm{n}} \mathrm{G} ; B, \mathrm{Ap}_{\mathrm{n}} \mathrm{G}\right)$ and of potential degradation products $(C$ and $D)$ Abscissae: $\log$ of concentration in $\mathrm{M}$.

the $\mathrm{Gp}_{\mathrm{n}} \mathrm{Gs}$ and the $A \mathrm{p}_{\mathrm{n}} \mathrm{Gs}$ act as growth modulators together with the platelet-derived growth factor in VSMCs in concentrations $\geq 10^{-9} \mathrm{M}$ (Fig. 5, $A$ and $B$ ). As with vasoconstrictor effects, growth stimulation together with PDGF cannot be attributed to degradation products of the dinucleoside polyphosphates (Fig. 5, $C$ and $D$ ). The growth stimulatory effects of the dinucleoside polyphosphates alone were apparent in concentrations $\geq 100 \mathrm{nM}$ (Fig. $6, A$ and $B$ ). $\mathrm{Gp}_{5} \mathrm{G}$ and, among $A \mathrm{p}_{\mathrm{n}} \mathrm{G}$, $\mathrm{Ap}_{5} \mathrm{G}$, appear to be most effective with respect to cell proliferation. The order of potency of the direct growth-promoting effect as well as of the PDGF-potentiating effect was $\mathrm{Gp}_{5} \mathrm{G}>$ $A p_{5} \mathrm{G}>\mathrm{Gp}_{6} \mathrm{G}>\mathrm{Gp}_{3} \mathrm{G}>>\mathrm{Ap}_{6} \mathrm{G}>\mathrm{Ap}_{4} \mathrm{G}>>\mathrm{Gp}_{4} \mathrm{G}>$ $\mathrm{Ap}_{3} \mathrm{G}$. The threshold concentrations for the direct growth stimulatory action were $10^{-7} \mathrm{M}$ for $\mathrm{Gp}_{5} \mathrm{G}, 10^{-6} \mathrm{M}$ for $\mathrm{Ap}_{5} \mathrm{G}$, and $10^{-5} \mathrm{M}$ for the other compounds. Indirect effects by degradation products could largely be excluded (Fig. 6, $C$ and $D$ ).

To clarify the mechanism of action of the dinucleoside polyphosphates, it is of interest to know how fast these molecules are degraded by ectonucleotidases of the VSMCs. VSMCs were incubated with dinucleoside polyphosphates, and the concentrations of the dinucleoside polyphosphates were chromatographically quantitated $(n=5)$. Half-lives of the dinucleoside polyphosphates were $49 \pm 6 \min \left(A_{3} G\right), 56 \pm 7 \mathrm{~min}\left(A_{4} G\right)$, $75 \pm 9 \min \left(\mathrm{Ap}_{5} \mathrm{G}\right), 65 \pm 9 \min \left(\mathrm{Ap}_{6} \mathrm{G}\right), 54 \pm 5 \min \left(\mathrm{Gp}_{3} \mathrm{G}\right)$, $62 \pm 8 \mathrm{~min}\left(\mathrm{Gp}_{4} \mathrm{G}\right), 72 \pm 10 \mathrm{~min}\left(\mathrm{Gp}_{5} \mathrm{G}\right)$, and $69 \pm 9 \mathrm{~min}\left(\mathrm{Gp}_{6} \mathrm{G}\right)$.

Recoveries of the respective dinucleoside polyphosphates in the effluate from the isolated perfused kidney were 83.5 $12.3 \%\left(\mathrm{Ap}_{3} \mathrm{G}\right), 79.4 \pm 9.7 \%\left(\mathrm{Ap}_{4} \mathrm{G}\right), 85.4 \pm 9.9 \%\left(\mathrm{Ap}_{5} \mathrm{G}\right)$, $81.0 \pm 10.3 \%\left(\mathrm{Ap}_{6} \mathrm{G}\right), 89.2 \pm 5.3 \%\left(\mathrm{Gp}_{3} \mathrm{G}\right), 87.3 \pm 8.7 \%\left(\mathrm{Gp}_{4} \mathrm{G}\right)$, $77.5 \pm 10.6 \%\left(\mathrm{Gp}_{5} \mathrm{G}\right)$, and $78.4 \pm 13.1 \%\left(\mathrm{Gp}_{6} \mathrm{G}\right)$ of the amount of $\alpha, \beta$ methylene ATP. In the effluate, no $\alpha, \beta$ methylene ADP was detected by chromatography.
Finally, the question arose whether the dinucleoside polyphosphates are released into the extracellular space, and whether by platelet aggregation extracellular concentrations (which affect VSMCs) are reached. Fig. $7 \mathrm{~A}$ depicts a chromatogram obtained from an untreated platelet suspension. Furthermore, the supernatant from an unstimulated platelet suspension was chromatographed. As shown in Fig. 7 B, the dinucleoside polyphosphates were not detectable in the supernatant from unstimulated platelets. Fig. $7 \mathrm{C}$ shows a chromatogram obtained from the supernatant of a platelet suspension after stimulation with thrombin. After platelet aggregation, the dinucleoside polyphosphates described above were found in the supernatant. Comparison with Fig. $7 A$ reveals that at least $60 \%$ of the dinucleoside polyphosphates are released by platelet aggregation. It can be estimated from the UV peaks that extracellular concentrations in the range of $0.5-3 \mu \mathrm{M}$ occur after thrombin stimulation.

\section{Discussion}

$A p_{3} G, A p_{4} G$, and $G_{4} G$ have been found in bacteria such as Escherichia coli, in yeast, and in crustaceans (16-19). Furthermore, $\mathrm{Ap}_{4} \mathrm{G}$ was isolated from Physarum polycephalum, rat

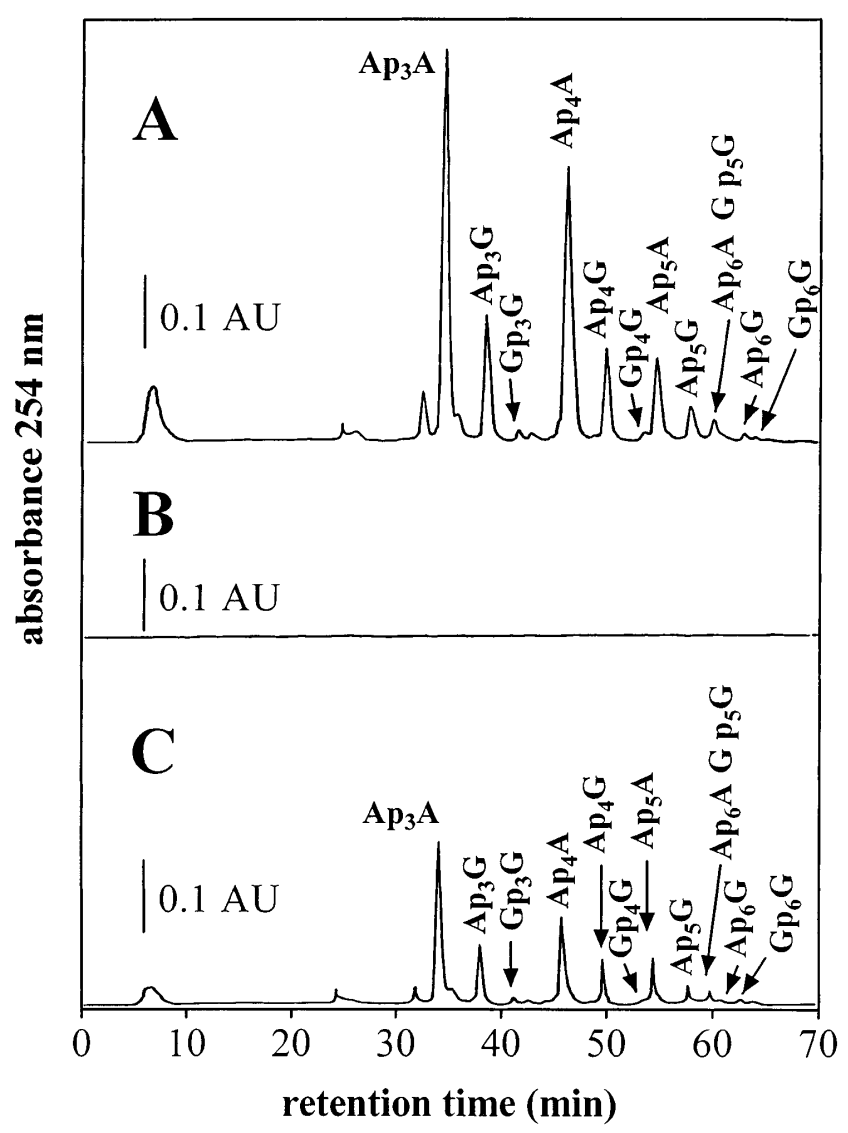

Figure 7. Anion exchange chromatography (according to step 4) of a platelet suspension $(A)$, a supernatant from an unstimulated platelet suspension $(B)$, and of a further supernatant from a platelet suspension aggregated with thrombin $(C)$. Representative tracings out of five similar experiments are shown. The peaks in $A$ and $C$ are labeled with the substances identified in the respective fraction by MALDIMS and retention times. 
liver, and Saccharomyces cerevisiae (20), but the physiological role in these organisms has not yet been elucidated. To the best of our knowledge, these compounds have not so far been isolated from human tissue.

Four classes of enzymes are known to synthesize dinucleoside polyphosphates in vitro: the aminoacyl-tRNA synthetases, $\mathrm{Ap}_{4} \mathrm{~A}$ phosphorylases, guanylyltransferases, and luciferases (for review see reference 21). The aminoacyl-tRNA synthetases catalyze the reaction of aminoacyl-AMP with NDP (or NTP) resulting in $A p_{3} \mathrm{~N}$ (or $A p_{4} \mathrm{~N}$ ) and the aminoacid (22).

A guanylyltransferase from yolk platelets of Artemia catalyzes the interaction of two molecules of GTP to form $\mathrm{Gp}_{4} \mathrm{G}$ with the release of inorganic pyrophosphate (23). $\mathrm{Gp}_{3} \mathrm{G}$ may be synthesized by this enzyme when GDP interacts with $\mathrm{Gp}_{4} \mathrm{G}$. In the presence of $\mathrm{ADP}$ and $\mathrm{Gp}_{4} \mathrm{G}$, this enzyme catalyzes the synthesis of $A_{p} G$ (24). The pathways that have been described so far, however, are not capable of producing $A p_{5} \mathrm{G}, \mathrm{Gp}_{5} \mathrm{G}, \mathrm{Gp}_{6} \mathrm{G}$, or $A p_{6} \mathrm{G}$.

Dinucleoside polyphosphates are degraded by asymmetrical and symmetrical hydrolases and phosphorylases. The substrate specificity of these enzymes mainly depends on the number of phosphates of the dinucleoside polyphosphates. Phosphodiesterases, another group of dinucleoside polyphosphate-hydrolyzing enzymes have a broad substrate specificity (25). In blood, dinucleotides are primarily metabolized by plasma enzymes $(26,27)$.

The physiological concentrations of the dinucleoside polyphosphates in blood cannot be determined exactly. The concentration of $A p_{n}$ Gs and $G p_{n}$ Gs may be $\sim 1 / 200-1 / 500$ that of ATP, which can easily be identified in chromatograms of platelet extracts. Furthermore, it is not known if these compounds occur in human cells apart from platelets.

The present experiments showed that $A p_{n} G s$ and $\mathrm{Gp}_{n} \mathrm{Gs}$ act both as growth factors in VSMCs and can modulate the action of a peptide growth factor. As is known for the diadenosine polyphosphates $(28,29)$, the $A p_{n} G s$ and $G p_{n}$ Gs may also exert their effects after release by platelet aggregation. One hypothesis of atherogenesis is that the initial lesion is local endothelial damage followed by platelet adhesion and aggregation. This cascade causes the release of growth factors such as PDGF from platelets, which leads to VSMC proliferation. Apart from the known growth factors such as PDGF, it is clear that the $A p_{n}$ Gs and $G p_{n}$ Gs may also stimulate VSMC growth either directly or indirectly, thus modulating the effect of other growth factors.

It would seem that at least one adenosine moiety is required for vasoconstrictive action since the $A p_{n} G$ s both increase vascular tone and cellular growth, whereas the $\mathrm{Gp}_{\mathrm{n}} \mathrm{Gs}$ do not influence vascular tone, affecting only VSMC growth. Thus, vasoconstriction and proliferation appear to be mediated by different receptors. The vasoconstrictive action of $\mathrm{Ap}_{5} \mathrm{G}$ and $\mathrm{Ap}_{6} \mathrm{G}$ appears to be a direct effect, since all potential degradation products are considerably less active than these dinucleoside polyphosphates. Direct action is further supported by the finding that the dinucleoside polyphosphates are recovered from the isolated perfused kidney to a similar degree as the nonhydrolyzable compound $\alpha, \beta$ methylene ATP. Furthermore, these substances show half-lives in the range of $1 \mathrm{~h}$ in cell culture. Nevertheless, degradation products may also modulate biological actions of the dinucleoside polyphosphates. The receptors involved in the vasoconstrictive action of $\mathrm{Ap}_{\mathrm{n}} \mathrm{G}$ may be the $\mathrm{P}_{2 \chi}$ purinoceptor, as this subtype also appears to mediate similar actions of $A p_{n} \mathrm{~A}$ on vascular tone (30). This concept is supported by the fact that the order of potency $\left(\mathrm{Ap}_{5} \mathrm{G}>\mathrm{Ap}_{6} \mathrm{G}>\mathrm{Ap}_{4} \mathrm{G}\right)$ is comparable to that of the vasoconstrictive actions of diadenosine polyphosphates $\left(A p_{5} \mathrm{~A} \geq A p_{6} \mathrm{~A} \geq \mathrm{Ap}_{4} \mathrm{~A}\right)$ in rat mesenteric arteries (30). Nevertheless, at present a contribution of other $\mathrm{P}_{2}$ purinoceptors or even $\mathrm{P}_{1}$ purinoceptors cannot be excluded.

The receptor mediating vascular growth is not yet known. It may represent a novel $\mathrm{P}_{2}$ purinoceptor subtype. Alternatively, it may be identical with the $\mathrm{P}_{2 \mathrm{U}}$-purinoceptor, since ATP and GTP binding to this receptor cause similar mitogenic effects on VSMCs (31).

After isolation of the dinucleoside polyphosphates from platelets, their physiological relevance was examined. We were able to show that the dinucleoside polyphosphates are released by platelet aggregation with thrombin. Under these conditions, extracellular concentrations of dinucleoside polyphosphates occur, which, in view of the concentration response curves observed, appear to be capable of affecting VSMCs. It may therefore be assumed that the dinucleoside polyphosphates identified in this study may indeed play a role for the events occurring in the vascular wall secondary to platelet aggregation.

In conclusion, human platelets contain not only diadenosine polyphosphates (7), but also $\mathrm{Ap}_{\mathrm{n}} \mathrm{Gs}$ and $\mathrm{Gp}_{\mathrm{n}} \mathrm{Gs}(n=3-6)$. These dinucleoside polyphosphates appear to form a large family of substances with different physiological actions that may play a role in regulation of organ perfusion and of vascular growth under physiological and pathological conditions.

\section{Acknowledgments}

We thank W. Potthoff for valuable technical assistance. We are also grateful to Dr. Paul Cullen for his help in correcting the manuscript.

This work was supported by the Deutsche Forschungsgemeinschaft (grant Schl 406/1-1 and grant Zi 315/5-1).

\section{References}

1. Fredholm, B.B., M.P. Abbracchio, G. Burnstock, J.W. Daly, T.K. Harden, K.A. Jacobson, P. Leff, and M. Williams. 1994. Nomenclature and classification of purinoceptors. Pharmacol. Rev. 46:143-156.

2. Schulze-Lohoff, E., S. Zanner, A. Ogilvie, and R.B. Sterzel. 1992. Extracellular ATP stimulates proliferation of cultured mesangial cells via $\mathrm{P}_{2}$-purinergic receptors. Am. J. Physiol. 263:F374-F383.

3. Malam-Souley, R., M. Campan, A.-P. Gadeau, and C. Desgranges. 1993. Exogenous ATP induces a limited cell cycle progression of arterial smooth muscle cells. Am. J. Physiol. 264:C783-C788.

4. Erlinge, D., H. Yoo, L. Edvinsson, D.J. Reis, and C. Wahlestedt. 1993. Mitogenic effects of ATP on vascular smooth muscle cells vs. other growth factors and sympathetic cotransmitters. Am. J. Physiol. 265:H1089-H1097.

5. Dalziel, H.H., and D.P. Westfall. 1994. Receptors for adenine nucleotides and nucleosides: subclassification, distribution and molecular characterization. Pharmacol. Rev. 46:449-466.

6. Aalkjaer, C. 1990. Regulation of intracellular $\mathrm{pH}$ and its role in vascular smooth muscle function. J. Hypertens. 8:197-206.

7. Schlüter, H., E. Offers, G. Brüggemann, M. van der Giet, M. Tepel, E. Nordhoff, M. Karas, C. Spieker, H. Witzel, and W. Zidek. 1994. Diadenosine phosphates and the physiological control of blood pressure. Nature. 367:186-188.

8. Pintor, J., and M.T. Miras-Portugal. 1995. A novel receptor for diadenosine polyphosphates coupled to calcium increase in rat midbrain synaptosomes. Br. J. Pharmacol. 115:895-902.

9. Barnes, L.D., A.K. Robinson, C.H. Mumford, and P.N. Garrison. 1985. Assay of diadenosine tetraphosphate hydrolytic enzymes by boronate chromatography. Anal. Biochem. 144:296-304.

10. Nordhoff, E., A. Ingendoh, R. Cramer, A. Overberg, B. Stahl, M. Karas, and F. Hillenkamp. 1992. Matrix-assisted laser desorption/ionization mass spectrometry of nucleic acids with wavelengths in the ultraviolet and infrared. Rapid Commun. Mass Spectrom. 6:771-776.

11. Kaufmann, R., D. Kirsch, and B. Spengler. 1994. Sequencing of peptides 
in a time-of-flight mass spectrometer: evaluation of postsource decay following matrix-assisted laser desorption ionisation (MALDI). Int. J. Mass Spectrom. Ion Proc. 131:355-385.

12. Ng, K.E., and L.E. Orgel. 1987. The action of water-soluble carbodiimide on adenosine-5' -polyphosphates. Nucleic Acids Res. 15:3573-3580.

13. Sulkowski, E., and S. Laskowski. 1971. Inactivation of 5'-nucleotidase in commercial preparations of venom exonuclease (phosphodiesterase). Biochim. Biophys. Acta. 240:443-447.

14. Heidenreich, S., M. Tepel, H. Schlüter, B. Harrach, and W. Zidek. 1995. Regulation of rat mesangial cell growth by diadenosine phosphates. J. Clin. Invest. 95:2862-2867.

15. Agha, A., H. Schlüter, S. König, K. Biel, M. Tepel, and W. Zidek. 1992. A novel platelet-derived renal vasoconstrictor agent in normotensives and essential hypertensives. J. Vasc. Res. 29:281-289.

16. Lever, A.F. 1990. Slow pressor mechanisms in hypertension: a role for hypertrophy of resistance vessels. J. Hypertens. 8:1065-1066.

17. Palfi, Z., G. Suranyi, and G. Borbely. 1991. Alterations in the accumulation of adenylylated nucleotides in heavy-metal-ion-stressed and heat-stressed Synechococcus sp. strain PCC 6301, a cyanobacterium, in light and dark. Biochem. J. 276:487-491.

18. Avila, D.M., A.K. Robinson, V. Kaushal, and L.D. Barnes. 1991. A paradoxical increase of a metabolite upon increased expression of its catabolic enzyme: the case of diadenosine tetraphosphate $\left(\mathrm{Ap}_{4} \mathrm{~A}\right)$ and $\mathrm{Ap}_{4} \mathrm{~A}$ phosphorylase I in Saccharomyces cerevisiae. J. Bacteriol. 173:7875-7880.

19. Prescott, M., A.D. Milne, and A.G. McLennan. 1989. Characterization of the bis $\left(5^{\prime}\right.$-nucleosidyl) tetraphosphate pyrophosphohydrolase from encysted embryos of the brine shrimp Artemia. Biochem. J. 259:831-838.

20. Redon, J., and D.C. Batlle. 1994. Regulation of intracellular $\mathrm{pH}$ in the spontaneously hypertensive rat: role of bicarbonate-dependent transporters. Hypertension. 23:503-512.

21. Muallem, S., D. Blissard, E.J. Cragoe, Jr., and G. Sachs. 1988. Activation of the $\mathrm{Na}^{+} / \mathrm{H}^{+}$and $\mathrm{Cl}^{-} / \mathrm{HCO}^{-}$exchange by stimulation of acid secretion in the parietal cell. J. Biol. Chem. 263:14703-14711.

22. Zamecnik, P.C., M.L. Stephenson, C.M. Janeway, and K. Randerath 1966. Enzymatic synthesis of diadenosine tetraphosphate and diadenosine triphosphate with a purified lysyl-sRNA synthetase. Biochem. Biophys. Res. Commun. 24:91-97.

23. Ng, L.L., and C. Dudley. 1989. Intracellular pH clamping of human leucocytes: a technique for determination of cellular buffering power and $\mathrm{Na}^{+} / \mathrm{H}^{+}$ antiporter characteristics. Clin. Sci. 77:417-423.

24. Tepel, M., T. Klaus, S. Laukemper, H. Schlüter, and W. Zidek. 1996. Increased lymphocytic $\mathrm{Na}^{+} / \mathrm{H}^{+}$exchange activity after hemodialysis: evidence for an endogenous inhibitor of $\mathrm{Na}^{+} / \mathrm{H}^{+}$exchange in patients with end-stage renal failure. Life Sci. 59:1545-1552.

25. Guranowski, A., and A. Sillero. 1992. Enzymes cleaving dinucleoside polyphosphates. In $\mathrm{Ap}_{4} \mathrm{~A}$ and Other Dinucleosides Polyphosphates. A.G. McLennan, editor. CRC Press, Inc., Boca Raton, FL. 81-133.

26. Lüthje, J., and A. Ogilvie. 1984. Diadenosine triphosphate $\left(\mathrm{Ap}_{3} \mathrm{~A}\right) \mathrm{me}$ diates human platelet aggregation by liberation of ADP. Biochem. Biophys. Res. Commun. 118:704-709.

27. Lüthje, J., and A. Ogilvie. 1988. Catabolism of $A_{4} A$ and $A p_{3} A$ in whole blood. The dinucleotides are long-lived signal molecules in the blood ending up as intracellular ATP in the erythrocytes. Eur. J. Biochem. 173:241-251.

28. Lüthje, J., and A. Ogilvie. 1983. The presence of diadenosine $5^{\prime}, 5^{\prime}$ $\mathrm{P} 1, \mathrm{P} 3-$ triphosphate $\left(\mathrm{Ap}_{3} \mathrm{~A}\right)$ in human platelets. Biochem. Biophys. Res. Com mun. 115:253-260.

29. McLennan, A.G. 1992. Ap 4 A and Other Dinucleoside Polyphosphates. CRC Press Inc., Ann Arbor, MI

30. Ralevic, V., C.H.V. Hoyle, and G. Burnstock. 1995. Pivotal role of phosphate chain length in vasoconstrictor versus vasodilator actions of adenine dinucleotides in rat mesenteric arteries. J. Physiol. 483(Pt.3):703-713.

31. Erlinge, D., J. You, C. Wahlestedt, and L. Edvinsson. 1995. Characterisation of an ATP receptor mediating mitogenesis in vascular smooth muscle cells. Eur. J. Pharmacol. Mol. Pharmacol. 289:135-149. 